\title{
Chemical Route for Synthesis of Citric Acid from Citrus Juices $^{\dagger}$
}

\author{
Naveen Prasad B.S. 1,", Sivamani Selvaraju ${ }^{1, *}$, Senthilkumar P. ${ }^{2, *}$ \\ 1 Chemical Engineering Section, Salalah College of Technology, Sultanate of Oman \\ 2 Department of Chemical Engineering, Sathyabama Institute of Science and Technology \\ * Correspondence: bsnaveenprasad@gmail.com (N.P.B.S); sivman.sel@ gmail.com (S.S.), sensen10@gmail.com (S.P); \\ $\dagger$ Presented at International e-Conference on Bioengineering for Health and Environment (ICBHE 2020)
}

Received: 5.07.2020; Revised: 10.07.2020; Accepted: 12.07.2020; Published: 15.07.2020

\begin{abstract}
Citric acid is the main tricarboxylic acid present in citrus fruits such as lemons, lime, oranges, grapefruit, grapes, etc. These fruits contain sufficient citric acid. The properties of citric acid make it an important additive for application in various industries such as the food, pharmaceuticals, disinfection, and cleaning industries. The aim of this experimental study is to produce citric acid from orange and grape juices. The chemical route for the synthesis of citric acid from citrus juices involves three steps: (i) Neutralization to adjust $\mathrm{pH}$ to 9-10 with $2.5 \mathrm{M} \mathrm{NaOH}$ solution, (ii) Addition of $\mathrm{CaCl}_{2}$ solution, and (iii) Acidification with $\mathrm{H}_{2} \mathrm{SO}_{4}$ solution to produce citric acid. Juice containing citric acid is neutralized with $\mathrm{NaOH}$ solution to obtain trisodium citrate. Then, trisodium citrate is added with $\mathrm{CaCl}_{2}$ solution to produce calcium citrate. Finally, calcium citrate is acidified with $\mathrm{H}_{2} \mathrm{SO}_{4}$ solution to collect crystals of citric acid. In this study, the fruits were crushed, juice filtered, neutralized, added $\mathrm{CaCl}_{2}$ solution, and acidified to obtain citric acid. The experiments were carried out by varying different volumes of $2.5 \mathrm{M}$ $\mathrm{NaOH}$ solution during neutralization, concentrations of $\mathrm{CaCl}_{2}$ solution, and volume of $\mathrm{H}_{2} \mathrm{SO}_{4}$ solution. The percentage of citric acid yield collected from grape juice varied from 44.1 to $79.53 \%$. Similarly, the percentage yield of citric acid was calculated to be from 60.1 to $96.3 \%$. It was found that the percentage of citric acid yield increased with increasing $\mathrm{pH}$ and decreased with increasing $\mathrm{CaCl}_{2}$ concentration. Thus, it could be concluded that the orange juice yielded more citric acid than grape juice.
\end{abstract}

Keywords: Orange juice; Grape juice; Neutralization; Acidification; Citric acid.

(C) 2020 by the authors. This article is an open-access article distributed under the terms and conditions of the Creative Commons Attribution (CC BY) license (https://creativecommons.org/licenses/by/4.0/).

\section{Funding}

This research received no external funding.

\section{Acknowledgments}

This research has no acknowledgment.

\section{Conflicts of Interest}

The authors declare no conflict of interest. 